\title{
Association of Serum Hepcidin Levels with Aerobic and Resistance Exercise: A Systematic Review
}

\author{
Phureephat Larsuphrom (D) and Gladys Oluyemisi Latunde-Dada * \\ Department of Nutritional Sciences, School of Life Course Sciences, King's College London, \\ Franklin-Wilkins-Building, 150 Stamford Street, London SE1 9NH, UK; phureephat.larsuphrom@kcl.ac.uk \\ * Correspondence: yemisi.latunde-dada@kcl.ac.uk
}

check for updates

Citation: Larsuphrom, P.; Latunde-Dada, G.O. Association of Serum Hepcidin Levels with Aerobic and Resistance Exercise: A Systematic Review. Nutrients 2021, 13, 393. https://doi.org/10.3390/nu13020393

Received: 28 December 2020

Accepted: 21 January 2021

Published: 27 January 2021

Publisher's Note: MDPI stays neutral with regard to jurisdictional claims in published maps and institutional affiliations.

Copyright: (c) 2021 by the authors. Licensee MDPI, Basel, Switzerland. This article is an open access article distributed under the terms and conditions of the Creative Commons Attribution (CC BY) license (https:// creativecommons.org/licenses/by/ $4.0 /)$.

\begin{abstract}
Background: Prevalence of iron deficiency is commonly reported among athletic population groups. It impairs physical performance due to insufficient oxygen delivery to target organs and low energy production. This is due to the high demand of exercise on oxygen delivery for systemic metabolism by the erythrocytes in the blood. Hepcidin, the key regulator of iron homeostasis, decreases to facilitate iron efflux into the circulation during enhanced erythropoiesis. However, acute anaemia of exercise is caused by increased hepcidin expression that is induced by stress and inflammatory signal. The study aimed to systematically review changes in serum hepcidin levels during resistance and aerobic exercise programmes. Methods: A systemic literature search from 2010 to April 2020 across seven databases comprised of Cochrane library, PubMed, Web of Science, Scopus, Embase, MEDLINE, and OpenGrey. The primary outcome was increased or decreased serum hepcidin from baseline after the exercise activity. Risks of bias were evaluated by using the National Institutes of Health (NIH) for quality assessment of before and after different exercise programmes. Results: Overall, twenty-three studies met the inclusion criteria. Out of the 23 studies, 16 studies reported significantly exercise-induced serum hepcidin elevation. Of the 17 studies that evaluated serum interleukin (IL)-6 levels, 14 studies showed significant exercise-induced serum IL-6 elevation. Changes in exercise-induced serum hepcidin and IL-6 levels were similar in both resistance and endurance exercise. Significant correlations were observed between post-exercise hepcidin and baseline ferritin levels $(r=0.69, p<0.05)$ and between post-exercise hepcidin and post-exercise IL-6 $(r=0.625, p<0.05)$. Conclusion: Resistance and endurance training showed significant increase in serum hepcidin and IL-6 levels in response to exercise. Baseline ferritin and post-exercise IL-6 elevation are key determining factors in the augmentation of hepcidin response to exercise.
\end{abstract}

Keywords: hepcidin; resistance; aerobic; IL-6; exercise; anaemia

\section{Introduction}

\subsection{Background}

Iron is an essential mineral for a number of physiological processes, and it is crucial for health and physical performance. It plays an essential role in the human body because it is involved in the production of oxygen-carrying proteins, haemoglobin, and myoglobin, which deliver oxygen to target tissues. Iron is also involved in energy formation within the electron transport chain, DNA synthesis, and in oxidative phosphorylation in the mitochondria [1]. These functions make iron an essential element that is relevant to physical performance. Therefore, iron deficiency (ID) leads to impaired energy metabolism due to reduced cytochrome production. This results in impaired ATP production and energy metabolism that contributes to detrimental exercise performance [2,3]. Iron deficiency also causes fatigue, exercise intolerance, impaired immune function and temperature regulation, and impairs the capability to adapt to high altitudes and stress [4,5]. Hence, an optimal iron status is required to maintain good exercise performance throughout the sports season. 


\subsection{Epidemiology of Iron Deficiency in Athletes}

ID is a common nutritional condition worldwide, and the number of cases with or without anaemia is $16 \%$ to $57 \%$ of female athletes and $1 \%$ to $31 \%$ of male athletes [6]. Although a high intake of iron is often promoted in athletes, the prevalence of ID is relatively high in athletes because iron absorption is negatively affected by physical exercise [7]. Haemoglobin and ferritin levels are lower in athletes compared to non-athletes [6]. The incidence of iron depletion in athletes who participate in endurance sports has been reported to be between $30 \%$ and $50 \%$, and this is due to gastrointestinal bleeding, haemolysis, haematuria, and inadequate iron intake [8]. High risk of iron depletion is observed in female athletes due to inadequate iron intake and blood loss during menstruation [9]. Athletes who are vegetarians are also at a high risk of ID due to low iron in plant-based foods that contain high levels of inhibitors such as phytate, fibre, and polyphenols. Dietary iron is absorbed when duodenal cytochrome $\mathrm{B}$ (DcytB) converts $\mathrm{Fe}^{3+}$ into $\mathrm{Fe}^{2+}$ in the intestinal lumen [10]. $\mathrm{Fe}^{2+}$ is transported across the cell membrane by the divalent metal transporter 1 (DMT1). Inside the cell, iron is stored as ferritin or transported out of the cell by ferroportin (FPN) into the blood circulation [11]. A study reported that a decrease in duodenal DMT1 and FPN was observed in rats after vigorous exercise compared to the controls [12]. This response causes reduced iron absorption, which compromises iron status in athletes [13].

\subsection{Hepcidin and Iron Metabolism}

Hepcidin is a peptide hormone that is produced by hepatocytes. It is known as a master regulator of iron homeostasis as it inhibits iron efflux from the duodenum, macrophages, and the placenta $[14,15]$. Hepcidin enhances the degradation and ubiquitination of ferroportin to inhibit iron release from the enterocyte into blood circulation. Hepcidin expression is regulated by iron status, erythropoiesis, inflammation, and hypoxia. Stress conditions such as anaemia and hypoxia promote erythropoiesis, which decreases hepcidin activity [16]. Suppression of hepcidin enhances increased iron entry into the plasma to meet the required high demand for iron delivery to the bone marrow for erythropoiesis. Some endurance athletes commonly undertake an exercise programme in hypoxic environments to improve performance because of increased red blood cell volume [17]. A hypoxic condition stimulates the kidney to produce erythropoietin (EPO), which promotes the proliferation of erythroid precursor cells. Increased EPO production by the kidney stimulates erythroferrone (ERFE) production. ERFE is a hormone that is produced by erythroblasts to inhibit hepcidin expression [18]. To induce hepcidin expression, ERFE binds to BMP6 and BMP6/BMP2 heterodimers to block BMP/SMAD signalling [19].

\subsection{Hepcidin, Interleukin-6, and Exercise}

Under inflammatory conditions, increased serum interleukin-6 (IL-6) activates hepcidin expression via JAK/STAT3 signalling cascades, resulting in the promotion of hepcidin transcription [20]. Exercise and physical activities increase physiological demand and promote inflammation, which influences hepcidin expression and results in the development of acute anaemia of exercise (AAE). Iron metabolism during AAE and the regulation of hepcidin expression are reviewed in [21]. This increase is magnified by increased IL-6 levels in response to exercise [22].

Changes in urinary hepcidin were first reported in women who had completed a marathon [23]. Most studies reported that a twofold to fourfold increase in serum hepcidin was detected following acute bouts of exercise at an intensity between $60 \%$ and $90 \%$ of $\mathrm{VO}_{2 \text { max }}$, peaking at $3 \mathrm{~h}$ after exercise [24-27]. The magnitude of these responses was mediated by baseline iron status and IL-6 [28,29]. By contrast, there was no significant difference in serum and urinary hepcidin levels in humans after submaximal cycling exercise [30,31].

Although there is a growing body of evidence on the subject, the relevance of hepcidin's response to exercise and iron deficiency anaemia has not sufficiently provided clear 
results to draw a firm conclusion. Moreover, most of the published studies investigated aerobic exercises, except a recent one that reported on resistance exercise. While resistance and aerobic exercise programmes are both important to professional athletes, they are also embraced by diverse groups in the population for long-term health benefits. Therefore, a comprehensive understanding of the changes in serum hepcidin in response to resistance and aerobic exercise will inform athletes and clinicians on the consequence of iron-deficiency anaemia and its management. The systematic review investigated changes in serum hepcidin levels during resistance and aerobic exercise programmes. Additionally, it aimed to evaluate the effect of exercise on serum IL-6 in athletes or recreationally trained subjects.

\section{Methods}

This systematic review was conducted in accordance with the Preferred Reporting Items for Systematic Reviews and Meta-Analyses guidelines 2009 (PRISMA 2009) [32]. Registration number: CRD42020188203.

\subsection{Eligibility Criteria}

The PICOS criteria are shown in Table 1. The inclusion criteria were as follows: (a) experimental studies that examined the effect of exercise on serum hepcidin and IL6 levels that were determined by valid methods, (b) studies conducted with athletes or recreationally trained participants, and (c) studies published in the English language. Systematic reviews, meta-analyses, surveys, abstract, and conference reports were excluded, as were studies conducted with animal models. Finally, studies that did not measure serum hepcidin levels or did not provide sufficient information to evaluate changes in serum hepcidin were excluded.

Table 1. PICOS criteria for inclusion and exclusion of studies.

\begin{tabular}{ccc}
\hline Criteria. & Inclusion & Exclusion \\
\hline Population & Athletes or recreationally trained subjects & Non-athletes or non-recreationally trained subjects \\
\hline Intervention/exposure & $\begin{array}{c}\text { Physical exercises, either resistance training or } \\
\text { aerobic training, at different intensity levels }\end{array}$ & Exercises that are not defined resistance or aerobic \\
\hline Comparator & $\begin{array}{c}\text { Exercise-induced changes in serum hepcidin and } \\
\text { IL-6 levels from baseline }\end{array}$ & \\
Outcome & $\begin{array}{c}\text { Primary and secondary outcomes are changes in } \\
\text { serum hepcidin and IL6 levels from baseline to } \\
\text { the last exercise training protocol, respectively. }\end{array}$ & $\begin{array}{c}\text { No evidence of quantitative data or sufficient } \\
\text { information to evaluate changes in serum hepcidin }\end{array}$ \\
\hline Study design & Experimental studies & $\begin{array}{c}\text { Systematic review } \\
\text { Meta-analysis }\end{array}$ \\
& & $\begin{array}{c}\text { Non-experimental studies } \\
\text { Conference report }\end{array}$
\end{tabular}

\subsection{Search Strategy and Identification of Studies}

The literature search was conducted across seven databases (Cochrane library, PubMed, Web of Science, Scopus, Embase, MEDLINE, and OpenGrey for unpublished literature) to select relevant experimental studies. The search strategy combined the following Medical Subject Heading (MeSH) and Embase thesaurus: Aerobic AND Resistance AND Exercise AND Hepcidin AND Experimental AND Urinary were the keywords used to search for the relevant studies. Subsequently, Aerobic OR Resistance OR Exercise OR Hepcidin OR Experimental studies OR Urinary hepcidin were also used to search for relevant studies. Finally, synonyms such as Cardiovascular OR Aerobic OR Workout OR Training OR Endurance OR Resistance were used to search for relevant studies.

Initially, obvious irrelevant studies were excluded after screening titles and abstracts. The full texts of the other remaining articles were carefully evaluated according to the 
eligibility criteria. Where required, and when in doubt, the eligibility for inclusion was resolved by two independent individuals (P.L.) and (G.O.L.D.).

\subsection{Data Extraction}

Data were extracted independently by two reviewers based on the following: name of the authors, publication year, country, number of participants, the proportion of female participants, mean age/age range of participants, population description, subject demographics, study setting, baseline characteristics, details of the intervention, study methodology, inclusion and exclusion criteria, recruitment, dropout rate, outcomes, and times of measurement information for the assessment of the risk of bias. The main findings, relevant results, and $p$-values were also reported. The second author reviewed the extracted data and both authors agreed on individual items that were vague and doubtful.

\subsection{Strategy for Data Synthesis}

We provide a narrative synthesis of the findings from the included studies based on the PICOS criteria. We also provide a narrative synthesis structured on the type of exercise intervention. For example, we compared different types of exercises (resistance vs. aerobic exercise) and different intensities of exercise (moderate vs. high intensity of aerobic exercise). The target population characteristics were analysed by considering sample size, gender, and age in order to assess the designs and exercise programmes before comparing each study. Continuous data were selected for the review so as to compare studies and reported data on the increase or decrease in serum hepcidin levels from baseline values. Mean differences in serum hepcidin responses were compared. Moreover, we assessed the validity of the methods used to analyse serum hepcidin levels to ensure the reliability and quality of the data in the studies included in the review.

\subsection{Assessment of Risk of Bias}

Two reviewers (P.L. and G.O.L.D.) used the quality assessment tools of the National Institutes of Health (NIH) for quality assessment of before-and-after studies without control groups. Two reviewers scored the 23 studies in this review across 12 questions in order to assess the internal validity of each study and, thus, ensure the overall high standard of each study. Depending on the study design, each of the 12 questions was answered with either "yes", "no", or "other cannot determine (CD), not reported (NR), not applicable (NA)". This allowed determination of the rating of each study as either "good", "fair", or "poor".

\subsection{Outcomes}

\subsubsection{Primary Outcome}

Changes in serum hepcidin levels from baseline to the last exercise training protocol. Measures of effect are an increase or decrease in these from baseline values.

\subsubsection{Secondary Outcome}

Changes in serum IL-6 levels from baseline to the last exercise training protocol. Measures of effect are an increase or decrease in these from baseline values.

\subsection{Analysis}

Serum hepcidin, urinary hepcidin, and IL-6 were converted to conventional units in order to compare them across all studies, i.e., $\mathrm{ng} / \mathrm{mL}, \mathrm{nM} / \mathrm{mmol} \mathrm{Cr}$, and $\mathrm{pg} / \mathrm{mL}$, respectively.

\section{Results}

\subsection{Identification and Selection of the Included Articles}

A summary of the study selection process is shown in Figure 1. A total of 550 articles were identified through seven databases (Cochrane Library, PubMed, Web of Science, Scopus, Embase, MEDLINE, and OpenGrey) since 2010. After duplicates were removed, 143 articles were further screened. Of these, 93 articles were excluded after assessing the 
title and abstracts, and the reasons for exclusion are shown in Figure 1. Fifty articles were evaluated for eligibility after reading the full-texts. A total of 27 articles were excluded because they were conference reports, lacked qualitative data, were selective bias reports, or had non-athletes as subjects (Figure 1).

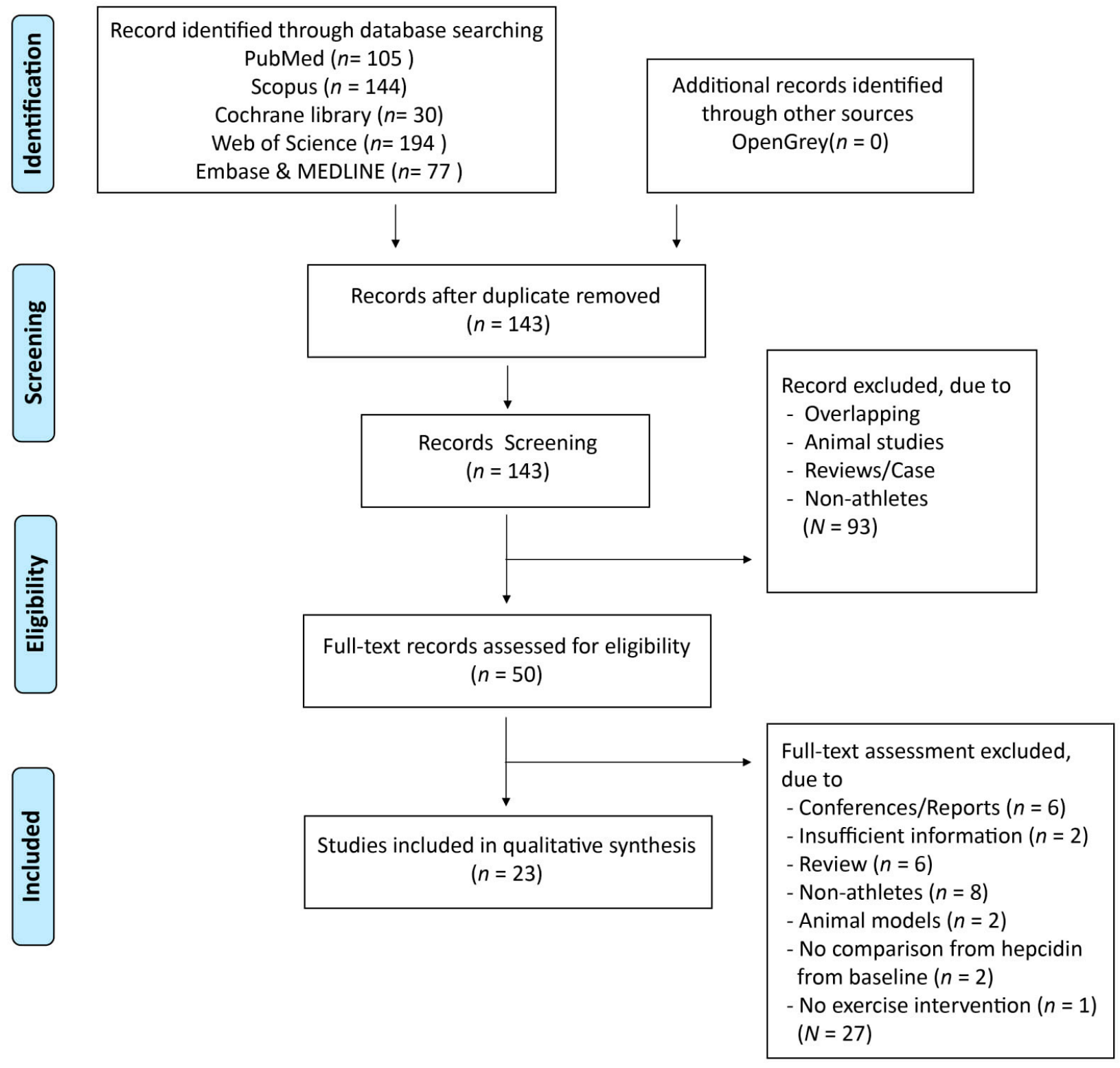

Figure 1. Flow diagram of selection process.

\subsection{Description and Characteristics of the Studies \\ 3.2.1. Participant Characteristics}

The 23 studies included in the current review (Table 2) comprised 376 participants (20 recreational participants and 356 athletes). Few studies had more than 20 participants, while most studies involved less than 20 participants. The average age of study participants ranged from 17.8 to 39.29 years, and the majority of the participants were men $(76.5 \%$ of all participants). Regarding geographic distribution, eleven studies were conducted in Europe (Poland, $n=5$; Slovenia, $n=2$; Germany, $n=2$; Spain, $n=1$; Switzerland, $n=1$ ). Eleven studies were conducted in Asia (Australia, $n=8$; Japan, $n=3$ ), while only one study was conducted in the USA (Table 2). 
Table 2. Characteristics of the studies.

\begin{tabular}{|c|c|c|c|c|c|c|c|}
\hline Study (Author/Year) & Design & Country & Sample Size & Sex & Age (Years) & Outcomes & Summary of Results \\
\hline Goto et al., 2020 [33] & $\begin{array}{l}\text { Cross-over } \\
\text { design }\end{array}$ & Japan & 10 & M & $23+1$ & $\begin{array}{l}\text { Hepcidin } \\
\text { IL-6 }\end{array}$ & $\begin{array}{l}\text { There was significantly elevated serum hepcidin after exercise }(p<0.001) \text {, } \\
\text { with significantly greater in the RE }(463 \pm 125 \%) \text { than in the endurance training } \\
\qquad(137 \pm 27 \%, p=0.03) \text {. } \\
\text { There were significantly increased plasma interleukin- } 6 \text { (IL-6) levels after exercise by } \\
2.2 \mathrm{pg} / \mathrm{mL} \text { in resistance training and by } 1.6 \mathrm{pg} / \mathrm{mL} \text { in endurance training }(p=0.003) \text {, } \\
\text { with no significant difference between the trials }\end{array}$ \\
\hline Tomczyk et al., 2020 [34] & $\begin{array}{l}\text { Single-arm } \\
\text { study }\end{array}$ & Poland & 29 & M & $39.29 \pm 8.58$ & Hepcidin & $\begin{array}{l}\text { The hormones that control iron metabolism induced by marathon depend on baseline } \\
\text { serum level of iron and ferritin. }\end{array}$ \\
\hline Dominguez et al., 2020 [31] & $\begin{array}{l}\text { Cross-over } \\
\text { design }\end{array}$ & Spain & 15 & M & $31.7 \pm 2.6$ & Hepcidin & There was no significant change in hepcidin level responses to different exercise levels. \\
\hline Bauer et al., 2018 [36] & $\begin{array}{l}\text { Single-arm } \\
\text { pilot study }\end{array}$ & Germany & $\begin{array}{l}31 \\
\mathrm{M}(19) \\
\mathrm{F}(12)\end{array}$ & $\mathrm{M} / \mathrm{F}$ & $\begin{array}{l}27.6 \pm 7.6 \text { (Males) } \\
27.7 \pm 4.5 \\
\text { (Females) }\end{array}$ & Hepcidin & $\begin{array}{l}\text { Significant increase in serum hepcidin by } 2.8 \mathrm{ng} / \mathrm{mL} \text { in men and by } 3.7 \mathrm{ng} / \mathrm{mL} \\
\text { in women. }\end{array}$ \\
\hline Goto et al., 2018 [37] & $\begin{array}{l}\text { Cross-over } \\
\text { design }\end{array}$ & Japan & 10 & M & $20.9 \pm 0.3$ & $\begin{array}{l}\text { Hepcidin } \\
\text { IL-6 }\end{array}$ & $\begin{array}{l}\text { There was significantly increased serum hepcidin compared to baseline for hypoxic and } \\
\text { normal conditions, but there was no significant difference between trials. }\end{array}$ \\
\hline Zugel et al., 2019 [39] & $\begin{array}{l}\text { Single-arm } \\
\text { study }\end{array}$ & Germany & 8 & M & $17.8 \pm 0.4$ & Hepcidin & $\begin{array}{l}\text { Cumulative training load can affect hepcidin. } \\
\text { No change in sTfR levels and ferritin index implied that erythropoiesis was not } \\
\text { influenced by iron compartmentalization via hepcidin. }\end{array}$ \\
\hline Peeling et al., 2017 [29] & $\begin{array}{l}\text { Single-arm } \\
\text { pilot study }\end{array}$ & Australia & 24 & M & $27.2 \pm 4.0$ & $\begin{array}{l}\text { Hepcidin } \\
\text { IL-6 }\end{array}$ & $\begin{array}{l}\text { There was significantly increased serum IL- } 6 \text { and hepcidin- } 25 \text { (by } 7.5 \mathrm{nM} \text { and } 8.2 \mathrm{pg} / \mathrm{mL} \text {, } \\
\text { respectively) in response to a } 25-\mathrm{km} \text { race-walk trial }(p<0.05) \text {. }\end{array}$ \\
\hline Moretti et al., 2018 [40] & $\begin{array}{l}\text { Single-arm } \\
\text { pilot study }\end{array}$ & Switzerland & 10 & M & $35(21-50)$ & $\begin{array}{l}\text { Hepcidin } \\
\text { IL-6 }\end{array}$ & $\begin{array}{l}\text { A 3-wk exercise resulted in increased serum IL-6, while there was decreased serum } \\
\text { hepcidin at the end of the study. }\end{array}$ \\
\hline Govus et al., 2017 [41] & $\begin{array}{l}\text { Cross-over } \\
\text { design }\end{array}$ & Australia & $\begin{array}{l}10 \\
\mathrm{M}(6) \\
\mathrm{F}(4)\end{array}$ & $\mathrm{M} / \mathrm{F}$ & $28.6 \pm 6.7$ & Hepcidin & 2 weeks of normobaric hypoxia suppressed resting hepcidin levels from 4 to $2 \mathrm{nM}$. \\
\hline
\end{tabular}


Table 2. Cont

\begin{tabular}{|c|c|c|c|c|c|c|c|}
\hline Study (Author/Year) & Design & Country & Sample Size & Sex & Age (Years) & Outcomes & Summary of Results \\
\hline Skarpanska et al., 2015 [42] & $\begin{array}{l}\text { Single-arm } \\
\text { pilot study }\end{array}$ & Poland & 20 & M & $21.3 \pm 0.82$ & $\begin{array}{l}\text { Hepcidin } \\
\text { IL-6 }\end{array}$ & $\begin{array}{l}\text { There were significant increases in IL- } 6 \text { by } 3.8 \mathrm{pg} / \mathrm{mL} \text { and in hepcidin by } 1.5 \mathrm{~nm} / \mathrm{mL} \\
\text { after exercise. }\end{array}$ \\
\hline Govus et al., 2014 [43] & $\begin{array}{c}\text { Cross-over } \\
\text { design }\end{array}$ & Australia & $\begin{array}{l}13 \\
M(7) \\
F(6)\end{array}$ & $\mathrm{M} / \mathrm{F}$ & $28.8 \pm 5.3$ & $\begin{array}{l}\text { Hepcidin } \\
\text { IL-6 }\end{array}$ & $\begin{array}{c}\text { Hepcidin levels significantly increased at } 3 \mathrm{~h} \text { post-exercise by } 0.85 \mathrm{nmol} / \mathrm{L} \text { in normoxia } \\
\text { and by } 1.48 \mathrm{nmol} \text { in hypoxia, with no significant differences between trials. } \\
\text { Significantly increased serum IL-6 immediately post-exercise by } 0.61 \mathrm{ng} / \mathrm{mL} \text { in normoxia } \\
\text { and by } 0.68 \mathrm{ng} / \mathrm{mL} \text {, but returned to baseline } 3 \mathrm{~h} \text { later. }\end{array}$ \\
\hline Sim et al., 2014 [44] & $\begin{array}{c}\text { Cross-over } \\
\text { design }\end{array}$ & Australia & 10 & M & $24 \pm 1$ & $\begin{array}{l}\text { Urinary } \\
\text { hepcidin } \\
\text { level }\end{array}$ & There was a significantly increased urinary hepcidin level $(p \leq 0.05)$. \\
\hline Peeling et al., 2014 [45] & $\begin{array}{l}\text { Single-arm } \\
\text { pilot study }\end{array}$ & Australia & $\begin{array}{l}54 \\
\mathrm{M}(38) \\
\mathrm{F}(16)\end{array}$ & $\mathrm{M} / \mathrm{F}$ & $25.8 \pm 6.6$ & $\begin{array}{l}\text { Hepcidin } \\
\text { IL-6 }\end{array}$ & $\begin{array}{c}\text { Significantly increased serum IL- } 6 \text { after exercise was observed when compared to } \\
\text { baseline within each group }(p<0.05) \text {. } \\
\text { Post-exercise hepcidin elevation was observed when the baseline serum ferritin was } \\
\text { above } 30 .\end{array}$ \\
\hline Badenhorst et al., 2014 [46] & $\begin{array}{c}\text { Cross-over } \\
\text { design }\end{array}$ & Australia & 10 & M & $26.6 \pm 10.7$ & $\begin{array}{l}\text { Hepcidin } \\
\text { IL-6 }\end{array}$ & $\begin{array}{l}\text { Significantly increased serum IL-6 immediately after exercise compared to baseline level, } \\
\text { but there was no difference between conditions. } \\
\text { There was significantly elevated serum hepcidin at } 3 \mathrm{~h} \text { post-exercise for both trials } \\
\text { compared to baseline, but it was significantly lower in the hypoxic condition. }\end{array}$ \\
\hline Antosiewicz et al., 2013 [47] & $\begin{array}{l}\text { Single-arm } \\
\text { pilot study }\end{array}$ & Poland & 21 & $\mathrm{M}$ & $22 \pm 1.5$ & $\begin{array}{l}\text { Hepcidin } \\
\text { IL-6 }\end{array}$ & $\begin{array}{l}\text { There was significantly increased serum IL- } 6 \text { and hepcidin at } 1 \mathrm{~h} \text { after exercise in both } \\
\text { groups }(p<0.05) \text {. } \\
\text { Hepcidin returned to baseline level in } 24 \mathrm{~h} \text { in judo athletes, whereas in control group, } \\
\text { it remained increased for } 5 \text { days following exercise. }\end{array}$ \\
\hline Auersperher et al., 2013 [48] & $\begin{array}{l}\text { Single-arm } \\
\text { pilot study }\end{array}$ & Slovenia & 14 & $\mathrm{~F}$ & $\begin{array}{l}31.4 \pm 5.9 \\
\text { for group } \\
\text { that had } \\
\text { ferritin levels } \\
>20 \mathrm{mg} / \mathrm{L} \\
34.9 \pm 4.7 \\
\text { for group } \\
\text { that had } \\
\text { ferritin levels } \\
<20 \mathrm{mg} / \mathrm{L}\end{array}$ & $\begin{array}{l}\text { Hepcidin } \\
\text { IL-6 }\end{array}$ & $\begin{array}{l}\text { There was no significant difference in serum IL- } 6 \text { and hepcidin levels during training } \\
\text { and baseline. However, hepcidin was significantly lower at recovery compared with } \\
\text { baseline }(p<0.05) .\end{array}$ \\
\hline
\end{tabular}


Table 2. Cont.

\begin{tabular}{|c|c|c|c|c|c|c|c|}
\hline Study (Author/Year) & Design & Country & Sample Size & Sex & Age (Years) & Outcomes & Summary of Results \\
\hline Sim et al., 2013 [25] & $\begin{array}{l}\text { Cross-over } \\
\text { design }\end{array}$ & Australia & 10 & M & $23 \pm 1$ & $\begin{array}{l}\text { Hepcidin } \\
\text { IL-6 }\end{array}$ & $\begin{array}{l}\text { Significant increases in post-exercise IL-6 level were seen within each trial }(p<0.05) \text { and } \\
\text { were significantly greater in H-R (by } 6 \mathrm{pg} / \mathrm{mL}) \text { than } \mathrm{L}-\mathrm{R}(p<0.05) \text {. } \\
\text { There was a significant increase in serum hepcidin levels at } 3 \mathrm{~h} \text { post-exercise within each } \\
\text { trial }(p<0.05) \text {. }\end{array}$ \\
\hline Newlin et al., 2012 [26] & $\begin{array}{l}\text { Cross-over } \\
\text { design }\end{array}$ & USA & 12 & $\mathrm{~F}$ & $19-32$ & $\begin{array}{l}\text { Hepcidin } \\
\text { IL-6 }\end{array}$ & $\begin{array}{l}\text { Hepcidin significantly increased at } 3 \mathrm{~h} \text { post-exercise then began to decline by } 6 \text { and } 9 \mathrm{~h} \\
\text { post-exercise. } \\
\text { IL-6 was significantly increased immediately post-exercise. }\end{array}$ \\
\hline Auersperger et al., 2012 [49] & $\begin{array}{l}\text { Single pilot } \\
\text { study }\end{array}$ & Slovenia & 18 & $\mathrm{~F}$ & $\begin{array}{c}\text { Interval group } \\
(N=10) \\
32.9 \pm 5.7 \text { years } \\
\text { Continuous group } \\
(N=8) \\
31.6 \pm 4.8 \text { years }\end{array}$ & $\begin{array}{l}\text { Hepcidin } \\
\text { IL-6 }\end{array}$ & $\begin{array}{c}\text { There was decreased serum hepcidin with time in TPost } 1 \text { and in BPost compared with } \\
\text { BPre }(p<0.001) \text { and increased in TPost } 2 \text { compared with TPost } 1(p<0.001) \text {. } \\
\text { IL-6 concentrations were not detected at all time points due to the plasma concentrations } \\
\text { being below } 2 \mathrm{ng} / \mathrm{L} .\end{array}$ \\
\hline Kasprowicz et al., 2013 [50] & $\begin{array}{l}\text { Single-arm } \\
\text { pilot study }\end{array}$ & Poland & 6 & M & $44.5 \pm 13.5$ & $\begin{array}{l}\text { Hepcidin } \\
\text { IL-6 }\end{array}$ & $\begin{array}{l}\text { A } 100-\mathrm{km} \text { run caused a progressive increase in blood IL- } 6 \text { concentration, which reached } \\
\text { the highest values after } 75 \mathrm{~km} \text {. } \\
\text { The } 100-\mathrm{km} \text { race did not affect blood hepcidin concentration. }\end{array}$ \\
\hline $\begin{array}{l}\text { Skarpanska-Stejnborn } \\
\text { et al., } 2019 \text { [51] }\end{array}$ & $\begin{array}{l}\text { Single pilot } \\
\text { study }\end{array}$ & Poland & 15 & M & $21 \pm 1$ & $\begin{array}{l}\text { Hepcidin } \\
\text { IL-6 }\end{array}$ & $\begin{array}{l}\text { There were significant increases in IL- } 6 \text { by } 4 \mathrm{pg} / \mathrm{mL} \text { and in hepcidin by } 0.2 \mathrm{ng} / \mathrm{mL} \text {. } \\
\text { The level of hepcidin and IL- } 6 \text { dropped to baseline after a 1-day recovery. }\end{array}$ \\
\hline
\end{tabular}


test at week 10; BPre $=$ Laboratory tests at baseline; TPost2 $=$ progressive training load at week $5-7$. 


\subsubsection{Study Design and Methods Used}

Of the 23 studies, 12 were single-arm pilot studies and 11 were cross-over designs published in the English language. Most of the studies conducted involved athletes, while nly two studies recruited recreationally trained participants. In terms of analysis of serum hepcidin and urinary hepcidin, 14 studies performed analyses using enzyme-linked immunosorbent assay (ELISA), while nine studies performed analyses using a combination of weak cation exchange chromatography and time-of-flight mass spectrometry (WCXTOF MS). A total of 17 studies determined both serum hepcidin and IL-6 levels, while six studies analysed only serum hepcidin.

Of the 23 selected studies, 22 were conducted during aerobic exercise training. Interestingly, the first study that compared resistance exercise to aerobic exercise and controls is included in the present review. Regarding the 22 studies that employed aerobic exercise, nine of them included non-weight-bearing exercises such as cycling and rowing, while the rest of the studies included weight-bearing exercises such as running, sprinting, or walking exercises. A total of 15 studies investigated high-intensity exercise as an intervention, while three studies were conducted during moderate-intensity exercise. Three studies evaluated both moderate- and high-intensity exercise. Six studies investigated the cumulative effect of exercise on serum hepcidin, while 17 of 23 studies assessed the effect of acute bouts of exercise on serum hepcidin.

\subsection{Outcome}

The main findings of studies that analysed serum hepcidin in response to different exercise protocols are summarised in Table 3.

\subsubsection{Serum Hepcidin and IL-6 Levels}

Most of the 16 studies revealed that exercise resulted in significantly increased serum hepcidin levels, while four studies reported significantly decreased serum hepcidin levels after exercise. Three studies demonstrated no significant changes in serum hepcidin levels after exercise. Out of 17 studies that evaluated serum IL-6, 14 reported significant exerciseinduced increases in serum IL-6 levels, and three studies reported no change in serum IL-6 levels after exercise.

\subsubsection{Risk of Bias within Studies}

Each study was assessed using the NIH Quality Assessment Tool for before-and-after (Pre-Post) studies without control groups (Supplementary Data). The majority of the studies had a "fair" risk of bias. The risk of bias of six studies was graded as "good". Five studies were graded as having a "poor" risk of bias.

Of the 23 studies included, 20 reported the eligibility criteria. Only five of the studies reported the sample size based on power and a significance level of 0.05. All studies used statistical methods to set $p$-values for the pre-to-post changes. A study dropout of more than $20 \%$ was observed in one study [34]. Most studies described clearly defined interventions regarding intensity and the exercise protocol, while two studies lacked exercise intensity specifications. 
Table 3. Summary of the studies evaluating the effect of exercise on serum hepcidin and IL-6 concentrations.

\begin{tabular}{|c|c|c|c|c|c|}
\hline Author & Population & $\begin{array}{l}\text { Sample } \\
\text { Size }\end{array}$ & Exercise Protocol & Time Points Measurement & Main Outcomes Pre vs. Post \\
\hline $\begin{array}{l}\text { Goto et al., } \\
2020 \\
{[33]}\end{array}$ & $\begin{array}{l}\text { Recreationally trained } \\
\text { males }\end{array}$ & 10 & $\begin{array}{c}\text { EP1: } \mathrm{RT} \text { at } 60 \% 1 \mathrm{RM}, 3-5 \text { sets } \times 12 \text { reps } \\
\text { EP2: END, } 65 \% \mathrm{VO}_{2 \max } \times 60 \mathrm{~min} \\
\text { EP3: Rest trial: reading books and watching DVDs }\end{array}$ & Pre, $1 \mathrm{~h}, 2 \mathrm{~h}, 3 \mathrm{~h}$, and $6 \mathrm{~h} \mathrm{PE}$ & $\begin{array}{l}\text { Hepcidin (Pre, } 3 \mathrm{~h} \text {, and } 6 \mathrm{~h} \mathrm{PE})(\mathrm{ng} / \mathrm{mL}): \\
\text { EP1: } \sim 8.0 \text { vs. } \sim 42 * \text { vs. } \sim 26^{*} \\
\text { EP2: } \sim 14 \text { vs. } \sim 32.5^{*} \text { vs. } \sim 20 \\
\text { IL-6 (Pre, } 0 \text { h, } 1 \text { h, and } 6 \mathrm{~h} \mathrm{PE})(\mathrm{pg} / \mathrm{mL}): \\
\text { EP1: } \sim 1.0 \text { vs. } \sim 3.9 * \text { vs. } \sim 4.1 * \text { vs. } \sim 3.5 \\
\text { EP2: } \sim 1.2 \text { vs. } \sim 4.2 * \text { vs. } \sim 2.9 \text { vs. } \sim 2.7 \\
\text { EP3: Pre and } 3 \mathrm{~h} \mathrm{PE} \\
\text { Hepcidin: } \sim 6 \text { vs. } \sim 9 \mathrm{~nm} / \mathrm{mL} \\
\text { Il-6: } \sim 1 \text { vs. } \sim 1.1 \mathrm{pg} / \mathrm{ml}\end{array}$ \\
\hline $\begin{array}{c}\text { Tomczyk et al., } \\
2020[34]\end{array}$ & Marathon runners & 29 & $\begin{array}{l}\text { Marathon } \\
\text { Long-distance continuous } \\
\text { running }\end{array}$ & $\begin{array}{c}\text { Pre (1 month before } \\
\text { the marathon) } \\
\text { Post- } 1 \text { sample } \\
\text { (after the marathon) } \\
\text { Post- } 2 \text { samples ( } 39 \pm 2 \text { days } \\
\text { after the competition) }\end{array}$ & $\begin{array}{c}\text { Hepcidin }(\mathrm{ng} / \mathrm{mL}) \\
1.12 \text { vs. } 1.09 * \text { vs. } 0.92\end{array}$ \\
\hline $\begin{array}{l}\text { McCormick } \\
\text { et al., } 2019 \text { [35] }\end{array}$ & $\begin{array}{c}\text { Endurance-trained runner } \\
\text { Males }\end{array}$ & 16 & $\begin{array}{l}\text { EP1: Running protocol }\left(65 \% \mathrm{VO}_{2 \max }\right) \text { in } \\
\text { the morning } \\
\text { EP2: running protocol }\left(65 \% \mathrm{VO}_{2 \max }\right) \text { in } \\
\text { the afternoon }\end{array}$ & Pre, $0 \mathrm{~h}$, and $3 \mathrm{~h} \mathrm{PE}$ & $\begin{array}{c}\text { Hepcidin (Pre and } 3 \text { h PE) }(\mathrm{ng} / \mathrm{mL}) \\
\text { EP1: } 1.11 \text { vs. } 6.69^{*} \\
\text { EP2: } 5.02 \text { vs. } 13.38^{*} \\
\text { IL-6 (Pre and } 3 \text { h PE) }(\mathrm{pg} / \mathrm{mL}) \\
\text { EP1: } 1 \text { vs. } 5.5^{*} \\
\text { EP2: } 6 \text { vs. } 9 \\
\text { Fractional iron absorption (breakfast vs. dinner) } \\
\text { EP1: } 8 \% \text { vs. } 7.5 \% \\
\text { EP2: } 7 \% \text { vs. } 6.9 \%\end{array}$ \\
\hline $\begin{array}{l}\text { Domínguez } \\
\text { et al., } 2020 \text { [31] }\end{array}$ & Trained cyclists & 15 & $\begin{array}{c}\text { EP1: 30-min moderate-intensity } \\
\text { continuous cycling } \\
\text { EP2: 30-min high-intensity continuous cycling }\end{array}$ & Pre- and Post-exercise & $\begin{array}{c}\text { Hepcidin(ng/mL) } \\
\text { EP1: } 1.28 \text { vs. } 1.29 \\
\text { EP2: } 1.28 \text { vs. } 1.24 \\
\text { Norepinephrine }(\mathrm{pg} / \mathrm{mL}) \\
\text { EP1: } 366.22 \text { vs. } 794.4 \\
\text { EP2: } 366.22 \text { vs. } 1622\end{array}$ \\
\hline
\end{tabular}


Table 3. Cont

\begin{tabular}{|c|c|c|c|c|c|}
\hline Author & Population & Sample Size & Exercise Protocol & Time Points Measurement & Main Outcomes Pre vs. Post \\
\hline $\begin{array}{c}\text { Bauer et al., } \\
2018 \text { [36] }\end{array}$ & Elite & 31 & $\begin{array}{l}\text { High-intensity exercise with } 70-80 \% \mathrm{VO}_{2 \max } \text { and } \\
\text { up to } 90-100 \% \mathrm{VO}_{2 \max } \text { in sprint distances } \\
200-1000 \mathrm{~m}\end{array}$ & Pre and $3 \mathrm{~h} \mathrm{PE}$ & $\begin{array}{c}\text { Hepcidin (Pre- and Post-exercise) }(\mathrm{ng} / \mathrm{mL}) \\
8.7 \text { vs. } 12^{*} \\
\text { Iron (Pre- and Post-exercise) }(\mu \mathrm{g} / \mathrm{dL}) \\
105.9 \text { vs. } 63.5^{*}\end{array}$ \\
\hline $\begin{array}{l}\text { Goto et al., } \\
2018 \text { [37] }\end{array}$ & Athletes & 10 & $\begin{array}{l}\text { EP1: exercise trials under normoxic conditions } \\
\qquad\left(\mathrm{FiO}_{2}: 20.9 \%\right) \\
\text { EP2: exercise trials under hypoxic conditions } \\
\left(\mathrm{FiO}_{2}: 14.5 \%\right)\end{array}$ & Pre, $0 \mathrm{~h}, 1 \mathrm{~h}$, and $3 \mathrm{~h} \mathrm{PE}$ & $\begin{array}{c}\text { Hepcidin (Pre, } 0 \text { h, } 1 \text { h, and } 3 \mathrm{~h} \mathrm{PE})(\mathrm{ng} / \mathrm{mL}) \\
\text { EP1: } 16 \text { vs. } 18 \text { vs. } 19 \text { vs. } 30^{*} \\
\text { EP2: } 11 \text { vs. } 13 \text { vs. } 10 \text { vs. } 19 * \\
\text { IL-6 (Pre, } 0 \text { h, } 1 \text { h, and } 3 \text { h PE) (pg/mL) } \\
\text { EP1: } 1.3 \text { vs. } 2.7^{*} \text { vs. } 2.5^{*} \text { vs. } 1.2 \\
\text { EP2: } 0.8 \text { vs. } 1.8^{*} \text { vs. } 2.2{ }^{*} \text { vs. } 1.0\end{array}$ \\
\hline $\begin{array}{l}\text { Goto et al., } \\
2017 \text { [38] }\end{array}$ & Endurance athletes & 10 & $\begin{array}{l}\text { EP1: HIT in endurance exercise under hypoxic } \\
\text { condition }\left(\mathrm{FiO}_{2}=14.5 \%\right) \\
\text { EP2: HIT in endurance exercise under a normoxic } \\
\text { condition }\left(\mathrm{FiO}_{2}=20.9 \%\right)\end{array}$ & Pre, $0 \mathrm{~h}, 1 \mathrm{~h}$, and $2 \mathrm{~h} \mathrm{PE}$ & $\begin{array}{c}\text { Hepcidin }(\mathrm{ng} / \mathrm{mL}) \\
\text { EP1: } 10.7 \text { vs. } 12.7 \text { vs. } 11.8 \text { vs. } 15.8 * \\
\text { EP2: } 7.9 \text { vs. } 10.1 \text { vs. } 9.7 \text { vs. } 13.2 * \\
\text { IL-6 (pg/mL) } \\
\text { EP1: } 0.6 \text { vs. } 5.2^{*} \text { vs. } 2.9 * \text { vs. } 2.0 * \\
\text { EP2: } 0.50 \text { vs. } 5.9 * \text { vs. } 3.4^{*} \text { vs. } 2.0 *\end{array}$ \\
\hline $\begin{array}{l}\text { Zügel et al., } \\
2020 \text { [39] }\end{array}$ & $\begin{array}{l}\text { Junior world elite } \\
\text { rowers }\end{array}$ & 8 & $\begin{array}{c}\text { A 4-week endurance training camp } \\
\text { EP1:D0: TV:104 km/wk (low training load) } \\
\text { EP2:D7: TV:180 km/wk (high training load) } \\
\text { EP3:D13:TV:202 km/wk (high training load) } \\
\text { EP4:D18:TV:170 km/wk (high training load) } \\
\text { EP5:D24:TV:133 km/wk (moderate training load) } \\
\text { EP6:D28:TV } 133 \mathrm{~km} / \mathrm{wk} \text { (moderate training load) }\end{array}$ & $\begin{array}{l}\text { Pre- and post-exercise } \\
\text { training at D } 0,7,13,18,24, \\
\text { and } 28\end{array}$ & $\begin{array}{c}\text { Hepcidin } \\
\text { EP1: 11.5 ng/mL } \\
\text { EP2: } \sim 23.2 * \mathrm{ng} / \mathrm{mL} \\
\text { EP3: } \sim 9.5 \mathrm{ng} / \mathrm{mL} \\
\text { EP4: } \sim 10.7 \mathrm{ng} / \mathrm{mL} \\
\text { EP5: } ~ 7.2 \mathrm{ng} / \mathrm{mL} \\
\text { EP6: } \sim 7.5 \mathrm{ng} / \mathrm{mL} \\
\text { Iron } \\
\text { EP1: } \sim 12 \mu \mathrm{mol} / 1 \\
\text { EP2: } \sim 17 \mu \mathrm{mol} / 1 \\
\text { EP3: } 18 \mu \mathrm{mol} / 1 \\
\text { EP4: } \sim 16 \mu \mathrm{mol} / 1 \\
\text { EP5: } 19 * \mu \mathrm{mol} / 1 \\
\text { EP6: } \sim 15 \mu \mathrm{mol} / 1\end{array}$ \\
\hline
\end{tabular}


Table 3. Cont

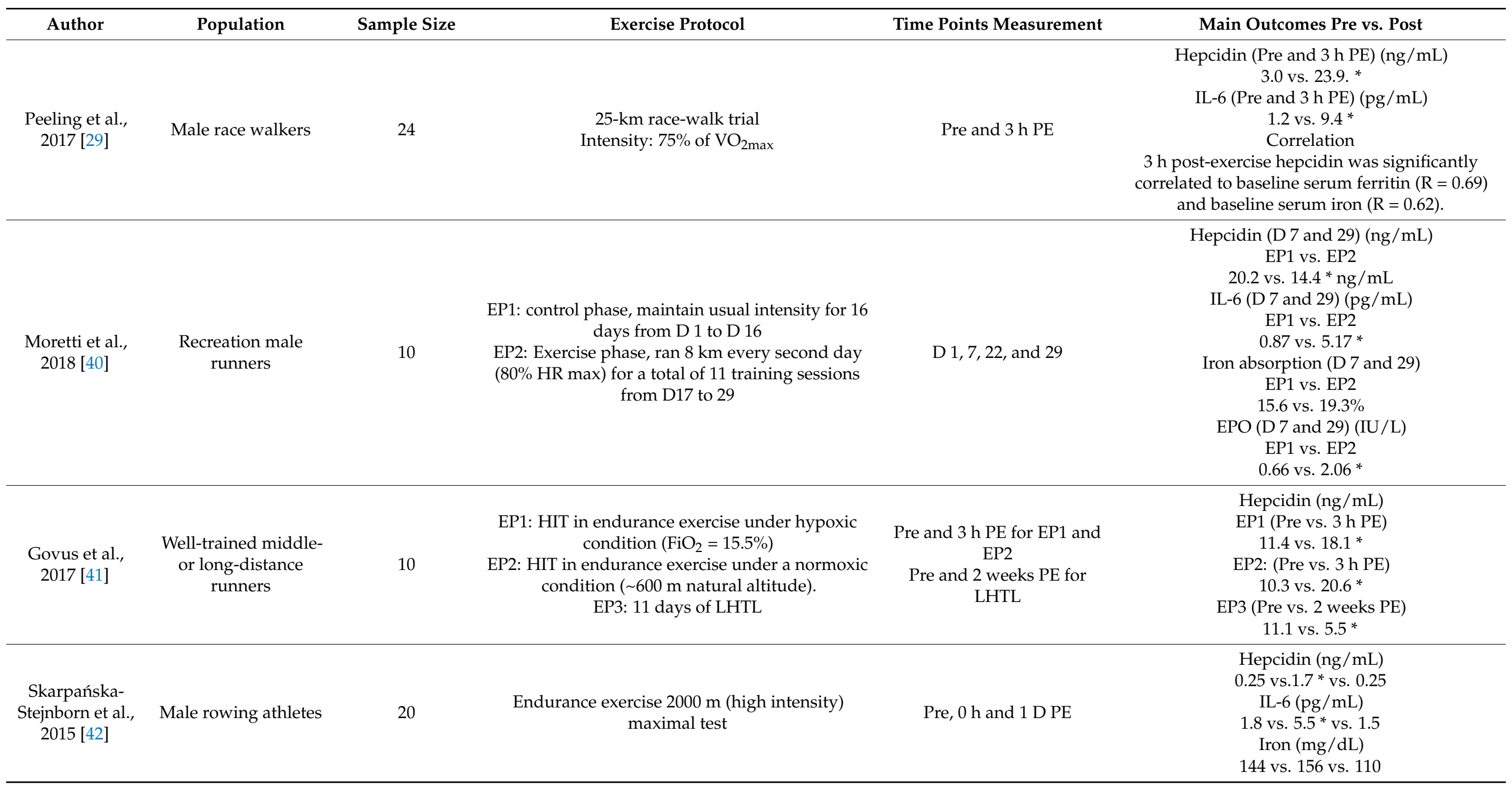


Table 3. Cont

\begin{tabular}{|c|c|c|c|c|c|}
\hline Author & Population & Sample Size & Exercise Protocol & Time Points Measurement & Main Outcomes Pre vs. Post \\
\hline $\begin{array}{l}\text { Govus et al., } \\
2014 \text { [43] }\end{array}$ & Endurance athletes & 13 & $\begin{array}{l}\text { EP1: HIT in endurance exercise under hypoxic } \\
\text { condition }\left(\mathrm{FiO}_{2}=14.5 \%\right) \\
\text { EP2: HIT in endurance exercise under a normoxic } \\
\text { condition }\left(\mathrm{FiO}_{2}=20.9 \%\right)\end{array}$ & Pre, $0 \mathrm{~h}$ and $3 \mathrm{~h} \mathrm{PE}$ & $\begin{array}{l}\text { Hepcidin }(\mathrm{ng} / \mathrm{mL}) \\
\text { Pre vs. } 3 \text { h PE } \\
\text { EC1: } 0.9 \text { vs. } 1.4 \text { * } \\
\text { EC2: } 1.0 \text { vs. } 1.3 * \\
\text { IL-6 (pg/mL) } \\
\text { Pre vs. } 3 \text { h PE } \\
\text { EC1: } 560 \text { vs. } 1240 \text { * } \\
\text { EC2: } 500 \text { vs. } 1100 \text { * }\end{array}$ \\
\hline
\end{tabular}

Urinary hepcidin $(\mathrm{nM} / \mathrm{mmol} \mathrm{Cr})$

$\mathrm{EP} 1$

D1: 0.46 vs. 1.19

D2: 0.76 vs. 1.38

Sim et al., 2014

[44]

Trained males

10

EP1: running with 78-89\% max HR

EP2: cycling with 78-89\% max HR

Pre and $3 \mathrm{~h}$ PE at D 1, 2 ,

and 6

D1: 0.52 vs. 0.64

D2: 0.85 vs. 0.84

D6: 0.43 vs. 0.80

Hepcidin $(\mathrm{ng} / \mathrm{mL})$

EC1: $\sim 2.5$ vs. $\sim 3.3$

EC 2: $\sim 5.8$ vs. $\sim 12.5$ *

EC 3: 6.1 vs. $~ 14.7 *$

EC1. Endurance exercise with serum ferritin

$$
<30 \mathrm{mg} / \mathrm{L}
$$

EC2. Endurance exercise with serum ferritin $30-50 \mathrm{mg} / \mathrm{L}$

Peeling et al., Trained runners or

$2014[45]$

triathletes

54

EC3. Endurance exercise with serum ferritin $50-100 \mathrm{mg} / \mathrm{L}$

EC4. Endurance exercise with serum ferritin $>100 \mathrm{mg} / \mathrm{L}$
Pre and $3 \mathrm{~h}$ PE

4: $\sim 9.4$ vs. $\sim 22.5$

IL-6 $(\mathrm{pg} / \mathrm{mL})$

EC 1: 1.3 vs. 3.8

EC 2: 1.1 vs. $3.5^{*}$

EC $3: 1.7$ vs. $4.3 *$

EC $4: 1.1$ vs. 5.6

Correlation

A significant moderate positive correlation between serum hepcidin and serum ferritin $(\mathrm{R}=0.52, p<0.05)$ 
Table 3. Cont

\begin{tabular}{|c|c|c|c|c|c|}
\hline Author & Population & Sample Size & Exercise Protocol & Time Points Measurement & Main Outcomes Pre vs. Post \\
\hline $\begin{array}{l}\text { Badenhorst } \\
\text { et al., } 2014 \text { [46] }\end{array}$ & $\begin{array}{l}\text { Well-trained male } \\
\text { endurance athletes }\end{array}$ & 10 & $\begin{array}{l}\text { Two } 8 \times 3 \text { min interval running sessions at } \\
\qquad 85 \% \mathrm{VO}_{2 \max }\end{array}$ & $\begin{array}{l}\text { Pre, } 3 \mathrm{~h} \text { and } 1 \mathrm{D} \text { (Hepcidin) } \\
\text { Pre and } 0 \mathrm{~h} \text { PE (IL-6) }\end{array}$ & $\begin{array}{c}\text { Hepcidin }(\mathrm{ng} / \mathrm{mL}) \\
\text { EC1: } 8.9 \text { vs. } 15.1^{*} \text { vs. } 8.7 \\
\text { EC2: } 9.0 \text { vs. } 20.6^{*} \text { vs. } 11.7 \\
\text { IL-6 }(\mathrm{pg} / \mathrm{mL}) \\
\text { EC1: } 1.32 \text { vs. } 2.99 * \\
\text { EC2: } 1.08 \text { vs. } 3.12 *\end{array}$ \\
\hline $\begin{array}{c}\text { Antosiewicz } \\
\text { et al., } 2013 \text { [47] }\end{array}$ & Male judo athletes & 21 & $\begin{array}{l}\text { Endurance exercise with high-intensity } 3 \times 30 \mathrm{~s} \\
\text { all-out sprint (cycle) }\end{array}$ & Pre, $1 \mathrm{~h}, 24 \mathrm{~h}$, and $5 \mathrm{D}$ PE & $\begin{array}{c}\text { Hepcidin }(\mathrm{ng} / \mathrm{mL}) \\
\text { EC1: } 64 \text { vs. } 83 * \text { vs. } 66 \text { vs. } 75 \\
\text { IL-6 (pg/mL) } \\
\text { EC1: } 1.25 \text { vs. } 2.2 * \text { vs. } 1.0 \text { vs. } 1.8\end{array}$ \\
\hline $\begin{array}{l}\text { Auersperger } \\
\text { et al., } 2013 \text { [48] }\end{array}$ & Runners & 14 & $\begin{array}{l}\text { Endurance exercise consists of one or two } \\
\text { interval trainings: } \\
\text {-One at } 88-95 \% \text { MHR, the second up to } \\
100 \% \text { MHR; } \\
\text {-Two easy runs (at } 70-87 \% \text { MHR) of } 6-8 \text { and } \\
12-18 \mathrm{~km} \text {. }\end{array}$ & Pre, $1 \mathrm{D}$, and $10 \mathrm{D}$ PE & $\begin{array}{c}\text { Hepcidin }(\mathrm{ng} / \mathrm{mL}) \\
\text { SF1: } 190 \text { vs. } 203 \text { vs. } 92.6^{*} \\
\text { SF2: } 173 \text { vs. } 134 \text { vs. } 102^{*} \\
\text { IL-6 levels were below a detectable } \\
\text { plasma concentration }\end{array}$ \\
\hline $\begin{array}{c}\text { Sim et al., } 2013 \\
{[25]}\end{array}$ & $\begin{array}{l}\text { Well-trained male } \\
\text { triathletes }\end{array}$ & 10 & 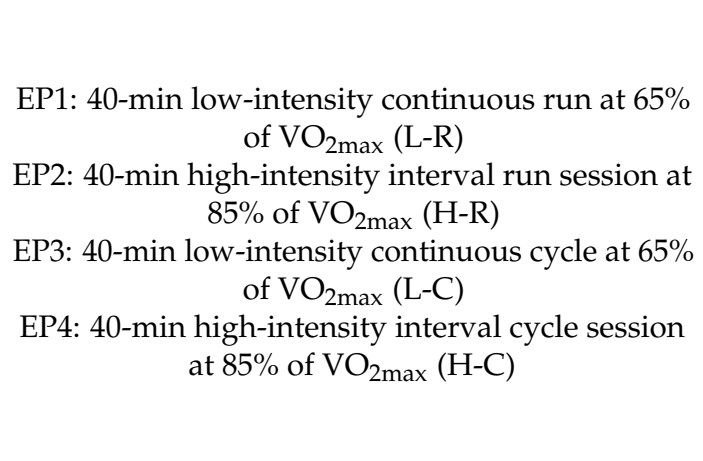 & Pre, $0 \mathrm{~h}$, and $3 \mathrm{~h} \mathrm{PE}$ & $\begin{array}{l}\text { Hepcidin }(\mathrm{ng} / \mathrm{mL}) \\
\text { Pre vs. } 3 \mathrm{~h} \mathrm{PE} \\
\text { EP1: } \sim 0.5 \text { vs. } \sim 0.7 * \\
\text { EP2: } \sim 0.5 \text { vs. } \sim 0.7 * \\
\text { EP3: } \sim 0.3 \text { vs. } \sim 0.5 * \\
\text { EP4: } \sim 0.3 \text { vs. } \sim 0.7 * \\
\text { IL-6 (pg/mL) } \\
\text { Pre vs. } 0 \text { h PE } \\
\text { EP1: } \sim 3.4 \text { vs. } \sim 4.5 * \\
\text { EP2: } \sim 3.5 \text { vs. } \sim 6.0^{*} \\
\text { EP3: } \sim 2.7 \text { vs. } \sim 4.9 * \\
\text { EP4: } \sim 3.1 \text { vs. } \sim 5.4 *\end{array}$ \\
\hline
\end{tabular}


Table 3. Cont

\begin{tabular}{|c|c|c|c|c|c|}
\hline Author & Population & Sample Size & Exercise Protocol & Time Points Measurement & Main Outcomes Pre vs. Post \\
\hline $\begin{array}{l}\text { Newlin et al., } \\
2012 \text { [26] }\end{array}$ & Runners & 12 & $\begin{array}{l}\text { EP1: } 60 \text {-min endurance exercise by treadmill } \\
\text { running at } 65 \% \text { of } \mathrm{VO}_{2 \mathrm{max}} \text {. } \\
\text { EP2: } 120 \text {-min endurance exercise by treadmill } \\
\text { running at } 65 \% \text { of } \mathrm{VO}_{2 \max } \text {. }\end{array}$ & $\begin{array}{c}\text { Pre, } 0 \mathrm{~h}, 3 \mathrm{~h}, 6 \mathrm{~h}, 9 \mathrm{~h} \text {, and } \\
24 \mathrm{~h} \mathrm{P}\end{array}$ & $\begin{array}{c}\text { Hepcidin }(\mathrm{ng} / \mathrm{mL}) \\
\text { EP1: } 0.23 \text { vs. } 0.25 \text { vs. } 0.57 * \text { vs. } 0.37 \text { vs. } 0.28 \\
\text { vs. } 0.23 \\
\text { EP2: } 0.31 \text { vs. } 0.34 \text { vs. } 1.38^{*} \text { vs. } 1.00 \text { vs. } 0.60 \\
\text { vs. } 0.43 \\
\text { IL-6 (pg/mL) } \\
\text { EP1: } 1.5 \text { vs. } 2.9 * \text { vs. } 1.9 \text { vs. } 1.6 \text { vs. } 1.8 \text { vs. } 1.4\end{array}$ \\
\hline $\begin{array}{l}\text { Auersperger } \\
\text { et al., } 2012 \text { [49] }\end{array}$ & $\begin{array}{l}\text { Trained female } \\
\text { runners }\end{array}$ & 18 & $\begin{array}{l}\text { EP1: Interval training exercise comprised of two } \\
\text { interval training (one at } 88-95 \% \mathrm{MHR} \text {, second up } \\
\text { to } 100 \% \mathrm{MHR} \text { ) and two easy runs at } 70-87 \% \\
\text { EP2: Continuous-training exercise comprised of } \\
\text { one easy interval training ( } 80-80 \% \mathrm{MHR} \text { ) and two } \\
\text { easy runs (at } 70-87 \% \mathrm{MHR} \text { ) } \\
\end{array}$ & $\begin{array}{c}\text { Pre (wk0) } \\
\text { TPost1 (wk 3) } \\
\text { TPost2 (wk 7) } \\
\text { Recovery1 (wk 4) } \\
\text { Recovery2 (wk 8) } \\
\text { Post-study (wk 10). } \\
\end{array}$ & $\begin{array}{c}\text { Hepcidin (ng/mL) } \\
\text { EP1: } 170 \text { vs. } 105^{*} \text { vs. } 170 \text { vs. } 190 \text { vs. } 180 \text { vs. } 115^{*} \\
\text { EP2: } 180 \text { vs. } 80^{*} \text { vs. } 140 \text { vs. } 135 \text { vs. } 125 \text { vs. } 90 \text { * }\end{array}$ \\
\hline $\begin{array}{l}\text { Kasprowicz } \\
\text { et al., } 2013 \text { [50] }\end{array}$ & $\begin{array}{l}\text { Male ultra-marathon } \\
\text { runners }\end{array}$ & 6 & Endurance exercise (running) $100 \mathrm{~km}$ & $\begin{array}{l}\text { Pre, } 25 \mathrm{~km}, 50 \mathrm{~km}, 75 \mathrm{~km} \text {, } \\
100 \mathrm{~km} \text {, and } 14 \mathrm{~h} \mathrm{PE}\end{array}$ & $\begin{array}{c}\text { Hepcidin }(\mathrm{ng} / \mathrm{mL}) \\
\sim 43 \text { vs. } \sim 44 \text { vs. } \sim 45 \text { vs. } \sim 42 \text { vs. } \sim 44 \text { vs. } \sim 47 \\
\text { IL-6 }(\mathrm{pg} / \mathrm{mL}) \\
\sim 1.9 \text { vs. } \sim 7.8^{*} \text { vs. } \sim 12.5^{*} \text { vs. } \sim 14 * \text { vs. } \sim 13 * \\
\text { vs. } \sim 5\end{array}$ \\
\hline $\begin{array}{l}\text { Skarpańska- } \\
\text { Stejnborn et al., } \\
2019[51]\end{array}$ & Elite rowers & 15 & $\begin{array}{l}\text { EP1: Endurance training during the preparatory } \\
\text { phase (trial I) } \\
\text { EP2: Endurance training during the competition } \\
\text { phase (trial II) (Total volumes were higher } \\
\text { than EP1) }\end{array}$ & Pre, $0 \mathrm{~h}$, and $1 \mathrm{D} P E$ & $\begin{array}{c}\text { Hepcidin }(\mathrm{ng} / \mathrm{mL}) \\
\text { Ep1: } 0.38 \text { vs. } 0.50 * \text { vs. } 0.36 \\
\text { EP2: } 0.38 \text { vs. } 0.85 * \text { vs. } 0.4 \\
\text { IL-6 (pg/mL) } \\
\text { EP1: } 2 \text { vs. } 6 * \text { vs. } 1.9 \\
\text { EP2: } 2.1 \text { vs. } 7.0 * \text { vs. } 1.8\end{array}$ \\
\hline
\end{tabular}

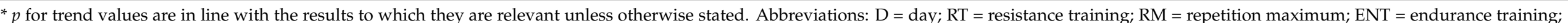

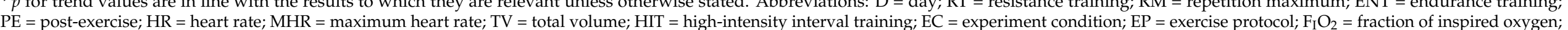

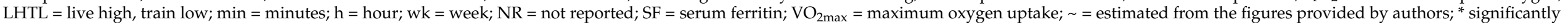
different from baseline levels. 


\section{Discussion}

\subsection{Summary of Evidence}

Exercise performance has been associated with elevated levels of serum hepcidin and IL-6 in athletes. This review revealed that the majority of the studies confirmed a significant increase in serum hepcidin (16 of 23 studies) and serum IL-6 levels (14 of 17 studies) in response to exercise. In general, a peak in hepcidin elevation was observed at $3 \mathrm{~h}$ after exercise [52]. Out of 16 studies that reported increased serum hepcidin in the current review, 11 showed increased hepcidin, with a peak at $3 \mathrm{~h}$ after exercise. However, others demonstrated the peak of hepcidin levels immediately or at 1 or $2 \mathrm{~h}$ after exercise $[38,47,51]$ instead. These latter studies that reported serum hepcidin elevations with a peak before $3 \mathrm{~h}$ after exercise excluded the 3-h time point, and the data showed increasing serum hepcidin over the time-course of the training exercise. The outcome of the current systematic review revealed that serum hepcidin's response to moderate- to high-intensity exercise occurs rapidly and reaches a peak at $3 \mathrm{~h}$, returning to baseline levels at $6 \mathrm{~h}$ after exercise. Different types of exercise modalities, either resistance or endurance training, did not differ in the 3-h peak in post-exercise serum hepcidin levels [33].

Exercise intensity reported in the current review comprises moderate and high intensities. The study reported elevated hepcidin concentration after high-intensity endurance training, reaching a peak at $3 \mathrm{~h}$ after exercise, similar to moderate intensity. However, there was no significant difference in the effect size of exercise-induced serum hepcidin elevation between high-intensity $\left(85 \% \mathrm{VO}_{2 \max }\right)$ and moderate-intensity exercise $\left(65 \% \mathrm{VO}_{2 \max }\right)$ [25]. The current review found a similar elevation in serum hepcidin in response to different exercise intensities from $60 \%$ to $90 \%$ of $\mathrm{VO}_{2 \max }$, thus indicating that exercise intensity may not be vital in the response of hepcidin to endurance training. However, the effects of low-intensity exercise on hepcidin remain unknown.

Apart from exercise intensity, training volume is proposed as an important factor in post-exercise hepcidin elevation. Although the current study showed a significant increase in serum hepcidin following $120 \mathrm{~min}$ vs. $60 \mathrm{~min}$ endurance exercise at the same intensity $\left(60 \%\right.$ of $\left.\mathrm{VO}_{2 \max }\right)$, a high training volume resulted in greater hepcidin levels than a low training volume $(60 \mathrm{~min})$ [26]. This result is in contrast to the result of a previous study that investigated a 40-min vs. 90-min endurance exercise at $75 \% \mathrm{VO}_{2 \max }$ and demonstrated that there was no significant difference in change in hepcidin levels between trials [44]. The contrasting findings may be due to a significantly higher fatigue level at $120 \mathrm{~min}$ as a result of reduced muscle glycogen, leading to a different hepcidin release [53]. However, the fatiguedependent mechanism was not supported by Kasprowic et al. [50], who evaluated the hepcidin response during and after a 100-km run ( $\sim 10 \mathrm{~h}$ long). The authors reported that despite the longer time and higher volume, there was no significant difference in serum hepcidin levels between exercise durations. Based on the current finding, training volume does not seem to be a vital factor in the response of hepcidin to endurance training.

Although there is a growing body of evidence regarding the fact that endurance exercise causes increased serum hepcidin levels, that of the effect of resistance training on serum hepcidin levels is scarce. A study on rats that compared resistance training to aerobic exercise showed an increase in haemoglobin concentration, without an impact on iron status, as well as an enhancement of iron absorption as a result of increased recycled iron [54]. The research demonstrated that energy expenditure during workouts is inversely correlated with increased hepcidin levels after exercise [55]. Resistance training is thought to be unlikely to stimulate hepcidin because of the lower energy that is expended. However, some other reports suggested that resistance training might induce inflammation due to reduced muscle glycogen and increased IL-6 expression [56,57]. Recently, Goto et al. [33] investigated the effect of resistance exercise and aerobic exercise on IL-6 and hepcidin $6 \mathrm{~h}$ after exercise in 10 recreationally trained males. The study found that a single bout of resistance exercise (RE) and endurance training (ENT) significantly elevated serum hepcidin, with a more significant increase in RE than in ENT at $3 \mathrm{~h}$. Serum IL-6 levels, however, increased immediately from baseline levels with no significant difference between the trials. 
This finding indicated that a greater increase in serum hepcidin levels after RT than after ENT was not augmented by IL-6.

Haemolysis has been linked to a mechanical impact on the body in some types of sports such as running and walking. Research shows that higher degrees of haemolysis were observed after intensity-matched running compared to a cycling session at $75 \% \mathrm{VO}_{2 \max }$, indicating that impact forces influence the rate of haemolysis [58]. Moreover, a study reported significantly increased levels of hepcidin in four separate exercise protocols in 10 triathletes that comprised cycling at moderate- and high-intensity and running at highand moderate-intensity regimes. The lowest magnitude of the effect was observed in moderate-intensity cycling compared to other trials, suggesting that athletes who are at risk of iron deficiency should perform moderate-intensity, non-weight bearing exercise [25]. However, some studies revealed that exercise-induced hepcidin elevation might occur in response to haemolysis, and it is not augmented by mechanical impact. Studies confirmed this assumption and found that different training surfaces did not influence serum hepcidin, inflammatory markers, and haemolysis in athletes [27,44]. Interestingly, Goto et al. [33] demonstrated that post-exercise serum iron elevation as an indirect marker of haemolysis was $10 \%$ higher in resistance exercise than in cycling. The increased iron loss from haemolysis can be a major factor that promotes hepcidin biosynthesis [59]. However, there are no studies that have evaluated the effect of resistance training on hepcidin compared to weight-bearing exercise (running). Therefore, future studies need to be conducted before concrete conclusions are drawn.

Hepcidin responses are sensitive to acute exercise bouts. However, studies that investigated cumulative effects of exercise are still scarce. Auersperger et al. [49] evaluated the effect of an 8-week endurance training programme on serum hepcidin levels and reported a decrease in serum hepcidin 3 weeks after training load. This was presumably caused by the increased requirement of iron in athletes as an adaptation process [13]. Furthermore, Auersperger et al. [48] reported that serum hepcidin decreased during an eight-week training programme regardless of the baseline iron status, and there was no significant change in C-reactive protein (CRP), indicating that the decreased serum hepcidin was associated with homeostatic regulation due to high iron demand rather than being a consequence of inflammation. This finding aligns with Moretti et al. [40] who reported decreased hepcidin and increased EPO after 3 weeks of an endurance exercise programme in recreational males as a consequence of erythropoietic drive influenced by exercise. Judging by the prevailing evidence, acute exercise seems to promote post-exercise serum hepcidin elevation, while long-term exercise training might attenuate exercise-induced increased hepcidin.

Another factor that accounts for variations in hepcidin response to exercise is the time of day when the activity is performed. A study evaluated the effect of morning versus afternoon exercise, i.e., a 90-min running protocol on iron absorption, including serum hepcidin and IL-6 levels. A twofold increase in serum hepcidin was observed in the afternoon trial, while a threefold increase was observed in the morning trial [35]. However, increased iron absorption was observed at breakfast after morning trials. This phenomenon can be explained either by a combination of a diurnal variation over the whole day or by some mechanisms that promote high iron absorption in the morning with a higher increase in serum hepcidin than that in the afternoon trial. These mechanisms require further investigation. In the same study, endurance training caused a significant twofold to fourfold increase in serum IL-6 levels at $3 \mathrm{~h}$ after exercise. This increase persisted throughout the day after the morning endurance training. These results agree with those of a previous study that reported a threefold to fivefold increase in serum IL-6 between the hours of 8:00 and 19:00 [60].

\subsection{Mechanism of Exercise-Induced Hepcidin and IL-6 Expression}

Baseline ferritin levels or iron status could determine hepcidin response to exercise. A study found that increased serum hepcidin was observed only in athletes with baseline 
ferritin levels above $30 \mu \mathrm{g} / \mathrm{mL}[45,52]$, indicating that low iron stores attenuate postexercise hepcidin elevation. The correlation between hepcidin and iron parameters was reported by Peeling et al. [29], who found a significant positive correlation between postexercise hepcidin levels and baseline ferritin levels $(r=0.69, p<0.01)$ [41]. A further study by Burden [61] showed that iron supplementation promoted increased hepcidin elevation after aerobic exercise in iron-deficient athletes. In the current systematic review, most of the studies reported post-exercise hepcidin elevation when the ferritin level was above $30 \mu \mathrm{g} / \mathrm{mL}$. Consequently, these studies indicate that the baseline iron status of athletes plays an important role in hepcidin' response to endurance exercise.

Exercise leads to increased physiological demand of energy, promotes inflammation, and increases IL-6 expression, which results in enhanced hepcidin expression [13]. This association was confirmed by Peeling et al. [29], who reported a significant correlation between $3 \mathrm{~h}$ post-exercise hepcidin and post-exercise serum IL-6 levels $(\mathrm{r}=0.625, p<0.05)$. This result was also in line with Banzet et al. [22]. The effect of exercise on serum IL-6 levels depends on the intensity and duration of the exercise. Sim et al. [25] reported a significant difference in serum IL-6 between high- and moderate-intensity running, while there was no difference between weight-bearing exercise (run trial) and non-weight-bearing exercise (cycle trial). This difference in the serum IL-6 response to different intensity exercises is in line with the observation made by Peeling et al. [27]. Moreover, repeated running exercise with intensity above $90 \% \mathrm{VO}_{2 \max }$ contributed to a significantly higher inflammatory response (IL-6) than that at the intensity of $75-80 \% \mathrm{VO}_{2 \max }$, resulting in a more considerable increase in hepcidin levels [62]. However, the effect of exercise on IL-6 was not affected by training volume and exercise modality [26]. In summary, the present review found that 15 of the 17 studies that measured serum IL-6 levels showed significant post-exercise IL-6 elevation, reaching peak values immediately after exercise.

Hypoxia is another factor known as a negative regulator of hepcidin through hypoxiainducible factor $1 \alpha$ (HIF-1 $\alpha)$ [63]. Consistent with this concept, deletion of the von HippelLindau factor (VHL) gene that controls HIF- $1 \alpha$ in the liver cell caused decreased hepcidin levels and increased ferroportin levels [64]. In a human trial, Badenhorst et al. [46] found a significant decrease in hepcidin concentration at $3 \mathrm{~h}$ post-exercise under hypoxic conditions. By contrast, Govus et al. [41,43] reported a significant increase in hepcidin levels at $3 \mathrm{~h}$ post-exercise under hypoxic conditions, similar to the normoxic condition. Additionally, the author found that the magnitude of response of serum hepcidin to exercise under normoxic or hypoxic conditions is dependent on baseline ferritin levels. This result is consistent with the result of the study by Peeling et al. [29], who reported that baseline ferritin and iron levels could explain $77 \%$ of post-exercise hepcidin elevation. Therefore, baseline ferritin levels play a predominant role in increased hepcidin in response to exercise. However, the inconsistent results may be due to exposure time to the hypoxic condition, and a small increase in EPO after exercise under a hypoxic condition might not be enough to attenuate hepcidin synthesis.

Increased serum hepcidin in response to exercise, apart from the duodenum, also inhibits iron efflux from hepatocytes and splenic macrophages [59]. A study reported significant decreases in indicators of iron status (iron, ferritin, and total iron-binding capacity (TIBC)) following aerobic exercise [52], resulting in reduced iron into the bone morrow. Insufficient serum iron in the bone marrow decreases erythropoiesis, which results in an anaemic condition. Notably, Reinke et al. [65] reported that $27 \%$ of absolute iron deficiency was observed in senior elite rowers at the end of the competitive season. This was in line with the findings by Auersperger et al. [48], who reported that a decreased iron store by $71 \%$ was observed in runners at the end of the training phase.

The present review has some limitations. First, the studies included in this review were either single pilot studies or had a cross-over design wherein possible confounding factors were not reported. Second, there were no tools to standardise exercise intensity, and the use of $\mathrm{VO}_{2 \max }$ could be subject to misinterpretation. Third, as serum hepcidin is affected by the circadian rhythm, discrepancies in reported data could be due to the time at 
which the exercise was performed in the day. There are few reports regarding specific time points of measurement in some studies.

The strength of the present review relies on being the first to investigate the effects of both resistance and endurance training on serum hepcidin response. Moreover, the effects of long-term training on hepcidin, the types of exercise, volume, and duration of exercise regimes, and hepcidin's responses were also investigated. However, there is a dearth of research on resistance exercise and the association with the regulation of serum hepcidin levels, consequently; further research is, therefore, imperative.

\section{Conclusions}

Iron deficiency is common among athletes and causes deleterious effects on performance due to decreased oxygen delivery and reduced aerobic capacity. Hepcidin plays an important role in the regulation of erythropoiesis and iron absorption. The current review shows that resistance and endurance training both increased serum hepcidin and IL-6 levels in response to exercise. For endurance training, exercise intensities between $60 \%$ and $90 \% \mathrm{VO}_{2 \max }$ elevated serum hepcidin and IL-6 levels, reaching a peak at $3 \mathrm{~h}$ after exercise for hepcidin and immediately after exercise for IL-6. The magnitude of hepcidin response to exercise correlates with the baseline serum ferritin levels and post-exercise serum IL-6. An elevated serum hepcidin level reduces iron absorption and results in reduced erythropoiesis, culminating in iron deficiency and anaemia, which consequently impact exercise performance.

Supplementary Materials: The following are available online at https://www.mdpi.com/2072-6 643/13/2/393/s1. Supplementary Data: Risk of bias summary: review authors' judgements about each risk of bias item for each included study.

Author Contributions: P.L. and G.O.L.-D. conceived the study idea and designed the research; P.L. performed the literature searches and screened the articles G.O.L.-D. validated the screened articles. PL extracted all data with the input of G.O.L.-D., where necessary; P.L. wrote the original review; and G.O.L.-D. reviewed and edited the manuscript. All authors have read and agreed to the published version of the manuscript.

Funding: This research received no external funding.

Institutional Review Board Statement: Not applicable.

Informed Consent Statement: Not applicable.

Data Availability Statement: Data are contained in this article and supplementary material.

Conflicts of Interest: The authors declare no conflict of interest.

$\begin{array}{ll}\text { Abbreviations } \\ \text { AAE } & \text { Acute anaemia of exercise } \\ \text { BMP } & \text { Bone morphogenetic protein } \\ \text { DMT1 } & \text { Divalent metal transporter 1 } \\ \text { EPO } & \text { Erythropoietin } \\ \text { ERFE } & \text { Erythroferrone } \\ \text { Fe }^{2+} & \text { Ferrous iron } \\ \text { Fe }^{3+} & \text { Ferric iron } \\ \text { FPN } & \text { Ferroportin } \\ \text { HAMP } & \text { Hepcidin antimicrobial peptide } \\ \text { HIF } & \text { Hypoxia-inducible factor } \\ \text { ID } & \text { Iron deficiency } \\ \text { IL-6 } & \text { Interleukin-6 }\end{array}$


JAK/STAT3 The Janus kinase (JAK)-signal transducer and activator of transcription (STAT) 3

LSECs Liver sinusoidal endothelial cells

PICOS Population, Intervention, Comparison, Outcomes and Study (PICOS)

TfR2 Transferrin receptor 2

TIBC Total iron-binding capacity

VHL von Hippel-Lindau factor

$\mathrm{VO}_{2 \max } \quad$ Maximal oxygen uptake

CRP C-reactive protein

sTfR Soluble transferrin receptor

\section{References}

1. Hinton, P.S. Iron and the endurance athlete. Appl. Physiol. Nutr. Metab. 2014, 39, 1012-1018. [CrossRef] [PubMed]

2. DellaValle, D.M. Iron supplementation for female athletes: Effects on iron status and performance outcomes. Curr. Sports Med. Rep. 2013, 12, 234-239. [CrossRef] [PubMed]

3. DellaValle, D.M.; Haas, J.D. Iron supplementation improves energetic efficiency in iron-depleted female rowers. Med. Sci. Sports Exerc. 2014, 46, 1204-1215. [CrossRef] [PubMed]

4. Schumacher, Y.O.; Schmid, A.; Grathwohl, D.; Bültermann, D.; Berg, A. Hematological indices and iron status in athletes of various sports and performances. Med. Sci. Sports Exerc. 2002, 34, 869-875. [CrossRef] [PubMed]

5. Płoszczyca, K.; Langfort, J.; Czuba, M. The Effects of Altitude Training on Erythropoietic Response and Hematological Variables in Adult Athletes: A Narrative Review. Front. Physiol. 2018, 9, 375. [CrossRef] [PubMed]

6. Koehler, K.; Braun, H.; Achtzehn, S.; Hildebrand, U.; Predel, H.G.; Mester, J.; Schänzer, W. Iron status in elite young athletes: Gender-dependent influences of diet and exercise. Eur. J. Appl. Physiol. 2012, 112, 513-523. [CrossRef]

7. Parks, R.B.; Hetzel, S.J.; Brooks, M.A. Iron Deficiency and Anemia among Collegiate Athletes: A Retrospective Chart Review. Med. Sci. Sports Exerc. 2017, 49, 1711-1715. [CrossRef]

8. Peeling, P.; Dawson, B.; Goodman, C.; Landers, G.; Trinder, D. Athletic induced iron deficiency: New insights into the role of inflammation, cytokines and hormones. Eur. J. Appl. Physiol. 2008, 103, 381-391. [CrossRef]

9. Alaunyte, I.; Stojceska, V.; Plunkett, A. Iron and the female athlete: A review of dietary treatment methods for improving iron status and exercise performance. J. Int. Soc. Sports Nutr. 2015, 12, 38. [CrossRef]

10. McKie, A.T.; Barrow, D.; Latunde-Dada, G.O.; Rolfs, A.; Sager, G.; Mudaly, E.; Mudaly, M.; Richardson, C.; Barlow, D.; Bomford, A.; et al. An iron-regulated ferric reductase associated with the absorption of dietary iron. Science 2001, 291, 1755-1759. [CrossRef]

11. McKie, A.T.; Marciani, P.; Rolfs, A.; Brennan, K.; Wehr, K.; Barrow, D.; Miret, S.; Bomford, A.; Peters, T.J.; Farzaneh, F.; et al. A novel duodenal iron-regulated transporter, IREG1, implicated in the basolateral transfer of iron to the circulation. Mol. Cell 2000, 5, 299-309. [CrossRef]

12. Liu, Y.Q.; Chang, Y.Z.; Zhao, B.; Wang, H.T.; Duan, X.L. Does hepatic hepcidin play an important role in exercise-associated anemia in rats? Int. J. Sport Nutr. Exerc. Metab. 2011, 21, 19-26. [CrossRef] [PubMed]

13. Kong, W.N.; Gao, G.; Chang, Y.Z. Hepcidin and sports anemia. Cell Biosci. 2014, 4, 19. [CrossRef] [PubMed]

14. Nemeth, E.; Tuttle, M.S.; Powelson, J.; Vaughn, M.B.; Donovan, A.; Ward, D.M.; Ganz, T.; Kaplan, J. Hepcidin regulates cellular iron efflux by binding to ferroportin and inducing its internalization. Science 2004, 306, 2090-2093. [CrossRef] [PubMed]

15. Nicolas, G.; Bennoun, M.; Devaux, I.; Beaumont, C.; Grandchamp, B.; Kahn, A.; Vaulont, S. Lack of hepcidin gene expression and severe tissue iron overload in upstream stimulatory factor 2 (USF2) knockout mice. Proc. Natl. Acad. Sci. USA 2001, 98, 8780-8785. [CrossRef]

16. Nicolas, G.; Chauvet, C.; Viatte, L.; Danan, J.L.; Bigard, X.; Devaux, I.; Beaumont, C.; Kahn, A.; Vaulont, S.J. The gene encoding the iron regulatory peptide hepcidin is regulated by anemia, hypoxia, and inflammation. J. Clin. Investig. 2002, 110, 1037-1044. [CrossRef]

17. Son, H.J.; Kim, H.J.; Kim, J.H.; Ohno, H.; Kim, C.K. Erythropoietin, 2,3 DPG, oxygen transport capacity, and altitude training in adolescent Alpine skiers. Aviat. Space Environ. Med. 2012, 83, 50-53. [CrossRef]

18. Kautz, L.; Jung, G.; Valore, E.V.; Rivella, S.; Nemeth, E.; Ganz, T. Identification of erythroferrone as an erythroid regulator of iron metabolism. Nat. Genet. 2014, 46, 678-684. [CrossRef]

19. Wang, C.Y.; Xu, Y.; Traeger, L.; Dogan, D.Y.; Xiao, X.; Steinbicker, A.U. Erythroferrone lowers hepcidin by sequestering BMP2/6 heterodimer from binding to the BMP type I receptor ALK3. Blood 2020, 135, 453-456. [CrossRef]

20. Katsarou, A.; Pantopoulos, K. Basics and principles of cellular and systemic iron homeostasis. Mol. Asp. Med. 2020, 75, 100866. [CrossRef]

21. Latunde-Dada, G.O. Iron metabolism in athletes-achieving a gold standard. Eur. J. Haematol. 2013, 90, 10-15. [CrossRef] [PubMed]

22. Banzet, S.; Sanchez, H.; Chapot, R.; Bigard, X.; Vaulont, S.; Koulmann, N. Interleukin-6 contributes to hepcidin mRNA increase in response to exercise. Cytokine 2012, 58, 158-161. [CrossRef] [PubMed]

23. Roecker, L.; Meier-Buttermilch, R.; Brechtel, L.; Nemeth, E.; Ganz, T. Iron-regulatory protein hepcidin is increased in female athletes after a marathon. Eur. J. Appl. Physiol. 2005, 95, 569-571. [CrossRef] [PubMed] 
24. Sim, M.; Dawson, B.; Landers, G.; Wiegerinck, E.T.; Swinkels, D.W.; Townsend, M.A.; Trinder, D.; Peeling, P. The effects of carbohydrate ingestion during endurance running on post-exercise inflammation and hepcidin levels. Eur. J. Appl. Physiol. 2012, 112, 1889-1898. [CrossRef] [PubMed]

25. Sim, M.; Dawson, B.; Landers, G.; Swinkels, D.W.; Tjalsma, H.; Trinder, D. Effect of exercise modality and intensity on post-exercise interleukin-6 and hepcidin levels. Int. J. Sport Nutr. Exerc. Metab. 2013, 23, 178-186. [CrossRef]

26. Newlin, M.K.; Williams, S.; McNamara, T.; Tjalsma, H.; Swinkels, D.W.; Haymes, E.M. The effects of acute exercise bouts on hepcidin in women. Int. J. Sport Nutr. Exerc. Metab. 2012, 22, 79-88. [CrossRef] [PubMed]

27. Peeling, P.; Dawson, B.; Goodman, C.; Landers, G.; Wiegerinck, E.T.; Swinkels, D.W.; Trinder, D. Training surface and intensity: Inflammation, hemolysis, and hepcidin expression. Med. Sci. Sports Exerc. 2009, 41, 1138-1145. [CrossRef] [PubMed]

28. Peeling, P.; Dawson, B.; Goodman, C.; Landers, G.; Wiegerinck, E.T.; Swinkels, D.W.; Trinder, D. Effects of exercise on hepcidin response and iron metabolism during recovery. Int. J. Sport Nutr. Exerc. Metab. 2009, 19, 583-597. [CrossRef]

29. Peeling, P.; McKay, A.K.A.; Pyne, D.B.; Guelfi, K.J.; McCormick, R.H.; Laarakkers, C.M.; Swinkels, R.W.; Garvican-Lewis, L.A.; Ross, M.L.R.; Sharma, A.P.; et al. Factors influencing the post-exercise hepcidin-25 response in elite athletes. Eur. J. Appl. Physiol. 2017, 117, 1233-1239. [CrossRef]

30. Troadec, M.B.; Lainé, F.; Daniel, V.; Rochcongar, P.; Ropert, M.; Cabillic, F.; Perrin, M.; Morcet, J.; Loréal, O.; Olbina, G.; et al. Daily regulation of serum and urinary hepcidin is not influenced by submaximal cycling exercise in humans with normal iron metabolism. Eur. J. Appl. Physiol. 2009, 106, 435-443. [CrossRef]

31. Domínguez, R.; Vicente-Campos, D.; Renguea, P.; Chicharro, L.; Iglesias López, M.T.; Renguea, A.; Pérez, M.; López Chicharro, J. Effect of exercise intensity on the hepcidin response. Nutr. Clin. Diet. Hosp. 2020, 40, 141-148.

32. Liberati, A.; Altman, D.G.; Tetzlaff, J.; Mulrow, C.; Gøtzsche, P.C.; Ioannidis, J.P.; Clarke, M.; Devereaux, P.J.; Kleijnen, J.; Moher, D. The PRISMA statement for reporting systematic reviews and meta-analyses of studies that evaluate health care interventions: Explanation and elaboration. PLoS Med. 2009, 6, e1-e34. [CrossRef] [PubMed]

33. Goto, K.; Kojima, C.; Kasai, N.; Sumi, D.; Hayashi, N.; Hwang, H. Resistance exercise causes greater serum hepcidin elevation than endurance (cycling) exercise. PLoS ONE 2020, 15, e228766. [CrossRef] [PubMed]

34. Tomczyk, M.; Kortas, J.; Flis, D.; Kaczorowska-Hacm, B.; Grzybkowska, A.; Borkowska, A.; Lewicka, E.; Dąbrowska-Kugacka, A.; Antosiewicz, J. Marathon Run-induced Changes in the Erythropoietin-Erythroferrone-Hepcidin Axis are Iron Dependent. Int. J. Environ. Res. Public Health 2020, 17, 2781. [CrossRef]

35. McCormick, R.; Moretti, D.; McKay, A.K.A.; Laarakkers, C.M.; Vanswelm, R.; Trinder, D.; Cox, G.R.; Zimmerman, M.B.; Sim, M.; Goodman, C.; et al. The Impact of Morning versus Afternoon Exercise on Iron Absorption in Athletes. Med. Sci. Sports Exerc. 2019, 51, 2147-2155. [CrossRef]

36. Bauer, P.; Zeissler, S.; Walscheid, R.; Frech, T.; Hillebrecht, A. Acute effects of high-intensity exercise on hematological and iron metabolic parameters in elite male and female dragon boating athletes. Phys. Sportsmed. 2018, 46, 335-341. [CrossRef]

37. Goto, K.; Kasai, N.; Kojima, C.; Ishibashi, A. Postexercise serum hepcidin response to repeated sprInt. exercise under normoxic and hypoxic conditions. Appl. Physiol. Nutr. Metab. 2018, 43, 221-226. [CrossRef]

38. Goto, K.; Sumi, D.; Kojima, C.; Ishibashi, A. Post-exercise serum hepcidin levels were unaffected by hypoxic exposure during prolonged exercise sessions. PLoS ONE 2017, 12, e0183629. [CrossRef]

39. Zügel, M.; Treff, G.; Steinacker, J.M.; Mayer, B.; Winkert, K.; Schumann, U. Increased Hepcidin Levels During a Period of High Training Load Do Not Alter Iron Status in Male Elite Junior Rowers. Front. Physiol. 2020, 10, 1577. [CrossRef]

40. Moretti, D.; Mettler, S.; Zeder, C.; Lundby, C.; Geurts-Moetspot, A.; Monnard, A.; Swinkels, R.W.; Brittenham, G.M.; Zimmermann, M.B. An intensified training schedule in recreational male runners is associated with increases in erythropoiesis and inflammation and a net reduction in plasma hepcidin. Am. J. Clin. Nutr. 2018, 108, 1324-1333. [CrossRef]

41. Govus, A.D.; Peeling, P.; Abbiss, C.R.; Lawler, N.G.; Swinkels, D.W.; Laarakkers, C.M.; Thomas, K.; Peiffer, J.J.; Gore, C.J.; Garvican-Lewis, L.A. Live high, train low-Influence on resting and post-exercise hepcidin levels. Scand. J. Med. Sci. Sports 2017, 27, 704-713. [CrossRef] [PubMed]

42. Skarpańska-Stejnborn, A.; Basta, P.; Trzeciak, J.; Szcześniak-Pilaczyńska, Ł. Effect of intense physical exercise on hepcidin levels and selected parameters of iron metabolism in rowing athletes. Eur. J. Appl. Physiol. 2015, 115, 345-351. [CrossRef] [PubMed]

43. Govus, A.D.; Abbiss, C.R.; Garvican-Lewis, L.A.; Swinkels, D.W.; Laarakkers, C.M.; Gore, C.J.; Peeling, P. Acute hypoxic exercise does not alter post-exercise iron metabolism in moderately trained endurance athletes. Eur. J. Appl. Physiol. 2014, 114, $2183-2191$. [CrossRef] [PubMed]

44. Sim, M.; Dawson, B.; Landers, G.J.; Swinkels, D.W.; Tjalsma, H.; Wiegerinck, E.T.; Trinder, D.; Peeling, P. A seven day running training period increases basal urinary hepcidin levels as compared to cycling. J. Int. Soc. Sports Nutr. 2014, 11, 14. [CrossRef] [PubMed]

45. Peeling, P.; Sim, M.; Badenhorst, C.E.; Dawson, B.; Govus, A.D.; Abbiss, C.R.; Swinkels, D.W.; Trinder, D. Iron status and the acute post-exercise hepcidin response in athletes. PLoS ONE 2014, 9, e93002. [CrossRef]

46. Badenhorst, C.E.; Dawson, B.; Goodman, C.; Sim, M.; Cox, G.R.; Gore, C.J.; Tjalsma, H.; Swinkels, R.W.; Peeling, P. Influence of post-exercise hypoxic exposure on hepcidin response in athletes. Eur. J. Appl. Physiol. 2014, 114, 951-959. [CrossRef]

47. Antosiewicz, J.; Kaczor, J.J.; Kasprowicz, K.; Laskowski, R.; Kujach, S.; Luszczyk, M.; Radzimiński, Ł.; Ziemann, E. Repeated "all out" interval exercise causes an increase in serum hepcidin concentration in both trained and untrained men. Cell. Immunol. 2013, 283, 12-17. [CrossRef] 
48. Auersperger, I.; Škof, B.; Leskošek, B.; Knap, B.; Jerin, A.; Lainscak, M. Exercise-induced changes in iron status and hepcidin response in female runners. PLoS ONE 2013, 8, e58090. [CrossRef]

49. Auersperger, I.; Knap, B.; Jerin, A.; Blagus, R.; Lainscak, M.; Skitek, M.; Skof, B. The effects of 8 weeks of endurance running on hepcidin concentrations, inflammatory parameters, and iron status in female runners. Int. J. Sport Nutr. Exerc. Metab. 2012, 22, 55-63. [CrossRef]

50. Kasprowicz, K.; Ziemann, E.; Ratkowski, W.; Laskowski, R.; Kaczor, J.J.; Dadci, R.; Antosiewicz, J. Running a 100-km ultramarathon induces an inflammatory response but does not raise the level of the plasma iron-regulatory protein hepcidin. J. Sports Med. Phys. Fit. 2013, 53, 533-537.

51. Skarpańska-Stejnborn, A.; Basta, P.; Trzeciak, J.; Kafkas, E.; Latour, E.; Cieślicka, M. Effect of intense physical exercise on hepcidin levels and selected parameters of iron metabolism in two different trial of training. Sci. Sports 2019, 34, 167-174. [CrossRef]

52. Domínguez, R.; Sánchez-Oliver, A.J.; Mata-Ordoñez, F.; Feria-Madueño, A.; Grimaldi-Puyana, M.; López-Samanes, Á.; Pérez-López, A. Effects of an Acute Exercise Bout on Serum Hepcidin Levels. Nutrients 2018, 10, 209. [CrossRef] [PubMed]

53. Williams, J.H.; Batts, T.W.; Lees, S. Reduced Muscle Glycogen Differentially Affects Exercise Performance and Muscle Fatigue. ISRN Physiol. 2013, 2013. [CrossRef]

54. Fujii, T.; Matsuo, T.; Okamura, K. Effects of resistance exercise on iron absorption and balance in iron-deficient rats. Biol. Trace Elem. Res. 2014, 161, 101-106. [CrossRef]

55. Pasiakos, S.M.; Margolis, L.M.; Murphy, N.E.; McClung, H.L.; Martini, S.; Gundersen, Y.; Castellani, J.W.; Karl, J.P.; Teien, H.K.; Madslien, E.H.; et al. Effects of exercise mode, energy, and macronutrient interventions on inflammation during military training. Physiol. Rep. 2016, 4, e12820. [CrossRef]

56. Steinberg, G.R.; Watt, M.J.; McGee, S.L.; Chan, S.; Hargreaves, M.; Febbraio, M.A.; Stapleton, D.; Kemp, B.E. Reduced glycogen availability is associated with increased AMPKalpha2 activity, nuclear AMPKalpha2 protein abundance, and GLUT4 mRNA expression in contracting human skeletal muscle. Appl. Physiol. Nutr. Metab. 2006, 31, 302-312. [CrossRef]

57. Peake, J.M.; Roberts, L.A.; Figueiredo, V.C.; Egner, I.; Krog, S.; Aas, S.N.; Suzuki, K.; Markworth, J.F.; Coombes, J.S.; Cameron-Smith, D.; et al. The effects of cold water immersion and active recovery on inflammation and cell stress responses in human skeletal muscle after resistance exercise. J. Physiol. 2017, 595, 695-711. [CrossRef]

58. Telford, R.D.; Sly, G.J.; Hahn, A.G.; Cunningham, R.B.; Bryant, C.; Smith, J.A. Footstrike is the major cause of hemolysis during running. J. Appl. Physiol. 2003, 94, 38-42. [CrossRef]

59. Ganz, T. Hepcidin and iron regulation, 10 years later. Blood 2011, 117, 4425-4433. [CrossRef]

60. Vgontzas, A.N.; Papanicolaou, D.A.; Bixler, E.O.; Lotsikas, A.; Zachman, K.; Kales, A. Circadian interleukin-6 secretion and quantity and depth of sleep. J. Clin. Endocrinol. Metab. 1999, 84, 2603-2607. [CrossRef]

61. Burden, R.J.; Pollock, N.; Whyte, G.P.; Richards, T.; Moore, B.; Busbridge, M.; Srai, S.K.; Otto, J.; Pedlar, C. Effect of Intravenous Iron on Aerobic Capacity and Iron Metabolism in Elite Athletes. Med. Sci. Sports Exerc. 2015, 47, 1399-1407. [CrossRef] [PubMed]

62. Peeling, P.; Dawson, B.; Goodman, C.; Landers, G.; Wiegerinck, E.T.; Swinkels, D.W.; Trinder, D. Cumulative effects of consecutive running sessions on hemolysis, inflammation and hepcidin activity. Eur. J. Appl. Physiol. 2009, 106, 51-59. [CrossRef] [PubMed]

63. Hintze, K.J.; McClung, J.P. Hepcidin: A Critical Regulator of Iron Metabolism during Hypoxia. Adv. Hematol. 2011, $2011,510304$. [CrossRef] [PubMed]

64. Peyssonnaux, C.; Zinkernagel, A.S.; Schuepbach, R.A.; Rankin, E.; Vaulont, S.; Haase, V.H.; Nizet, V.; Johnson, R.S. Regulation of iron homeostasis by the hypoxia-inducible transcription factors (HIFs). J. Clin. Investig. 2007, 117, 1926-1932. [CrossRef] [PubMed]

65. Reinke, S.; Taylor, W.R.; Duda, G.N.; Haehling, S.; Reinke, P.; Volk, H.D.; Anker, S.D.; Doehner, W. Absolute and functional iron deficiency in professional athletes during training and recovery. Int. J. Cardiol. 2012, 156, 186-191. [CrossRef] [PubMed] 